\title{
Single-Step Synthesis of Manganese Ferrite Nanoparticles with Enhanced Magnetization via Chemical Co-precipitation Route
}

\author{
S. Pande ${ }^{1}$, M. M. Islam ${ }^{2 *}$, S. C. Mohanta ${ }^{1}$, Nasiruddin ${ }^{3}$ \\ ${ }^{1}$ Department of Chemistry, Jashore University of Science and Technology, Jashore -7408, \\ Bangladesh \\ ${ }^{2}$ Department of Chemistry, University of Rajshahi, Rajshahi - 6205, Bangladesh \\ ${ }^{3}$ Department of Chemistry, Bangabandhu Sheikh Mujibur Rahman Science and Technology \\ University, Gopalganj-8100, Bangladesh
}

Received 2 December 2018, accepted in final revised form 24 February 2019

\begin{abstract}
Single-domain manganese ferrite nanoparticles were synthesized through one-step chemical co-precipitation technique using diethanolamine which acted simultaneously as precipitating and capping agent. The synthesized nanoparticles were characterized by XRD, FTIR, TGA, EDX, FESEM and VSM. XRD pattern showed the presence of peaks corresponding to the single-phase inverse spinel structure with an average crystallite size of $59.6 \mathrm{~nm}$. The average particle size determined by FESEM was $46.8 \mathrm{~nm}$. In addition, the magnetic properties of the nanoparticles analyzed by VSM exhibited nearly superparamagnetic property with a high saturation magnetization of $77.31 \mathrm{emu} / \mathrm{g}$ with little coercivity $(10.53 \mathrm{emu} / \mathrm{g})$ and remanence $(9.32 \mathrm{emu} / \mathrm{g})$ at $300 \mathrm{~K}$ temperature. TGA and FTIR results confirmed the binding of diethanolamine onto the surface of manganese ferrite nanoparticles. The synthesized nanoparticles exhibited single crystalline phase with improved magnetic properties.
\end{abstract}

Keywords: Co-precipitation; Magnetic nanoparticles; Alkanolamine; Magnetization.

(C) 2019 JSR Publications. ISSN: 2070-0237 (Print); 2070-0245 (Online). All rights reserved.

doi: http://dx.doi.org/10.3329/jsr.v11i2.39059 J. Sci. Res. 11 (2), 225-234 (2019)

\section{Introduction}

Typical spinel-type ferrite nanoparticles possess some outstanding properties such as the large surface area to volume ratio derived from nanometer size, superparamagnetic behaviour and high saturation magnetization [1,2]. Such unique properties of ferrite nanoparticles make them a suitable candidate for various technological and biological applications [3-5]. The properties of ferrite nanoparticles are highly dependent on the composition, morphology and size which are strongly connected with the preparation conditions. This implies that such properties of ferrite nanoparticles can be tuned or engineered during the synthesis process. Many preparation routes such as hydrothermal,

\footnotetext{
*Corresponding author: m_m_chem@yahoo.com
} 
co-precipitation, thermal decomposition, sol-gel and reverse micelle have been developed to prepare the single-domain ferrite nanoparticles $[5,6]$.

Focusing on cost-effectiveness, synthetic time scale and easy scalability aqueous coprecipitation technique is one of the preferred choices for producing water-dispersible ferrite nanoparticles. The particles' morphology, composition, and magnetic properties synthesized by co-precipitation route are greatly affected by various factors like the type of salts used (e.g. chlorides, sulfates, nitrates), the precursors' ratio, the reaction temperature, the $\mathrm{pH}$ value and ionic strength of the media [2]. The control of the particle size distribution, crystallinity, and magnetic properties through this route is still challenging [2,6,7]. However, at the nanoscale, a reduction in the particle size often implies a decrease in the saturation magnetization due to the surface spin-canting effect $[8,9]$. This is especially noticed in ferrite nanoparticles prepared by co-precipitation since they exhibit greater structural disorder due to the increased contribution of the magnetic "dead" layer [10]. Furthermore, diamagnetic organic capping agents reduce the magnetic property of the synthesized nanoparticles significantly [11,12]. As the magnetic properties can be tuned by selecting appropriate synthetic methodology, it is inevitable to quest a suitable synthetic route for the preparation of spherical ferrite nanoparticles with high saturation magnetization, low coercivity, and low remanent magnetization for various applications. In this context, the quest for aqueous co-precipitation approaches that allow tuning of the particle size and magnetic properties remains an ongoing challenge.

It is worthwhile to mention that the use of suitable organic bases alternative to traditional inorganic bases such as $\mathrm{NaOH}, \mathrm{KOH}$ and so on offers multifold advantages. Those include the truncation of synthesis steps, reducing the synthesis time, avoiding the use of additional capping agent, and cost-effectiveness. In this view, C. Freire et al. [13] used first-time isopropanolamine and diisopropanolamine, homologues of alkanolamine series, to get the dual functions of co-precipitating and capping agent. They found improved magnetic properties of several ferrites through single-step synthesis. Diethanolamine (DEA) possesses excellent chelating properties due to having one or more hydroxyl groups and amines [14]. It can play an important role as both co-precipitating and capping agent which can prevent the agglomeration tendencies of synthesized particles and tunes the magnetic property (saturation magnetization) of manganese ferrite $\left(\mathrm{MnFe}_{2} \mathrm{O}_{4}\right)$ nanoparticles. To our best knowledge, there is no report on the use of DEA for the synthesis of $\mathrm{MnFe}_{2} \mathrm{O}_{4}$ nanoparticles in homogeneous aqueous solution. In this paper, the synthesis of $\mathrm{MnFe}_{2} \mathrm{O}_{4}$ nanoparticles in high yields through one-step co-precipitation route based on the use of DEA as co-precipitating together with capping agent and the characterization of synthesized material is reported.

\section{Experimental}

\subsection{Materials and reagents}

Iron (III) chloride hexahydrate ( $\geq 99.9 \%$ ), manganese (II) chloride tetrahydrate ( $\geq 99.9 \%$ ), diethanolamine (or 2,2'-Iminodiethanol) ( $\geq 99.5 \%$ ) were obtained from Merck, Germany. 
Ultrapure water (Millipore, specific resistivity $18.2 \mathrm{M} \Omega \mathrm{cm}$ ) was used throughout the experiments. All reagents were used without further purification.

\subsection{Synthesis of $\mathrm{MnFe}_{2} \mathrm{O}_{4}$ nanoparticles}

The $\mathrm{MnFe}_{2} \mathrm{O}_{4}$ magnetic nanoparticles were prepared by the aqueous co-precipitation of $\mathrm{Mn}$ (II) and $\mathrm{Fe}$ (III) chlorides $\left(\mathrm{Mn}^{\mathrm{II}} / \mathrm{Fe}^{\mathrm{III}}\right.$ ratio of 0.5 ) under alkaline conditions using DEA (or 2,2'-Iminodiethanol) as precipitating agent. Briefly, $50 \mathrm{~mL}$ of $0.1 \mathrm{M}(5 \mathrm{mmol})$ $\mathrm{MnCl}_{2} \cdot 4 \mathrm{H}_{2} \mathrm{O}$ solution and $100 \mathrm{~mL}$ of $0.1 \mathrm{M}(10 \mathrm{mmol}) \mathrm{FeCl}_{3} \cdot 6 \mathrm{H}_{2} \mathrm{O}$ solution were mixed at a pH 3 and heated at $50{ }^{\circ} \mathrm{C}$, afterwards quickly added to $100 \mathrm{~mL}$ of $3.0 \mathrm{M}$ DEA solution ( $\mathrm{pH}$ 11-12) under magnetic stirring. A black precipitate formed immediately and exhibited a strong magnetic response. The stirring was continued for $2 \mathrm{~h}$ at $100{ }^{\circ} \mathrm{C}$. The reaction was carried out at inert atmosphere of $\mathrm{N}_{2}$ gas. After that time, the reaction mixture was cooled to room temperature, and the precipitate was magnetically separated and washed with de-ionized water several times to remove the residual electrolyte. Finally, the sample was dried at $70{ }^{\circ} \mathrm{C}$.

\subsection{Physicochemical characterization}

Different analytical tools were employed to characterize the synthesized $\mathrm{MnFe}_{2} \mathrm{O}_{4}$ magnetic nanoparticles (MNPs). Powder X-ray Diffraction (XRD) measurements were performed at room temperature over the angle from 10 to $70^{\circ}\left(2 \theta^{\circ}\right)$ with monochromatic $\mathrm{CuK} \alpha$ radiation $(\lambda=1.5406 \AA$ ) using Philips X'Pert Pro diffractometer (PW 3040/60, Netherlands) under the Bragg-Brentano $\theta / 2 \theta$ configuration.

Fourier Transform IR (FTIR) spectra of $\mathrm{MnFe}_{2} \mathrm{O}_{4}$ magnetite nanoparticles were taken in $\mathrm{KBr}$ pellets (Merck, spectroscopic grade) containing $1 \mathrm{wt} \%$ MNPs. The measurements were made using a Perkin-Elmer FTIR spectrometer (1760X, USA). High signal-to-noise spectra were acquired at a nominal resolution of $4 \mathrm{~cm}^{-1}$ over the full spectral range $\left(400-4000 \mathrm{~cm}^{-1}\right)$ with an acquisition number of 32 .

Thermogravimetric (TG) Analysis of $\mathrm{MnFe}_{2} \mathrm{O}_{4}$ magnetic nanoparticles was used to determine the amount of adsorbed ligand mass on the nanoparticles. The experiments were performed using a Perkin-Elmer (STA 8000, USA) under a nitrogen atmosphere at a gas flow rate of $20 \mathrm{~mL} / \mathrm{min}$. The powder samples were heated at a constant rate of 20 ${ }^{\circ} \mathrm{C} / \mathrm{min}$ from 100 to $500{ }^{\circ} \mathrm{C}$ and held at $500{ }^{\circ} \mathrm{C}$ for $30 \mathrm{~min}$. The loss in mass after heating is accounted for the removal of water and organic moieties from solid nanoparticles.

The surface morphology of $\mathrm{MnFe}_{2} \mathrm{O}_{4}$ magnetic nanoparticles was observed with JEOL Field Emission Scanning Electron Microscope (FESEM) (JSM-7600F, Japan) operating at an accelerating voltage of $50 \mathrm{kV}$. The average particle sizes and size distributions were calculated from the diameters of at least 200 distinct particles randomly selected from the FESEM micrographs. The size of the nanoparticles was measured from the image using ImageJ software.

The magnetic properties of the dried $\mathrm{MnFe}_{2} \mathrm{O}_{4}$ magnetic nanoparticles were studied using a commercial MicroSense Vibration Sample Magnetometer (VSM), (EV9, USA). 
The isothermal magnetization $(\mathrm{M})$ versus applied magnetic field $(\mathrm{H})$ was performed over the temperature range $300 \mathrm{~K}$ with $\mathrm{H}$ up to $1000 \mathrm{Oe}$.

\section{Results and Discussion}

\subsection{Structure, composition and morphology}

Crystal structure of $\mathrm{MnFe}_{2} \mathrm{O}_{4}$ magnetic nanoparticles was analyzed by XRD technique. XRD pattern was shown in Fig. 1, from which it is observed that $\mathrm{MnFe}_{2} \mathrm{O}_{4}$ particles synthesized in the presence of DEA showed characteristics peaks at $2 \theta=18.71^{\circ}, 30.18^{\circ}$, $35.43^{\circ}, 37.51^{\circ}, 43.11^{\circ}, 52.15^{\circ}, 56.90^{\circ}$, and $62.59^{\circ}$ that can be assigned to (111), (220), (311), (222), (400), (422), (511) and (440) lattice planes of cubic unit cell of ferrite. The excellent matching of the observed peaks with JCPDS no. 10-0319 for $\mathrm{MnFe}_{2} \mathrm{O}_{4}$ without invisibility of any peaks in the diffraction patterns supported the formation of single-phase ferrite with cubic spinel crystallite structure. Furthermore, peak broadening and slight small value, $8.493 \AA$ of lattice parameter estimated from diffraction pattern compared to bulk counterparts (8.499 $\AA$ for $\mathrm{MnFe}_{2} \mathrm{O}_{4}$, JCPDS no. 10-0319) evidenced the particles of fine crystallite size [15]. The average crystallite size was calculated using the Debye-Scherrer approximation (Eq.1),

$$
\mathrm{D}=\frac{\mathrm{K} \lambda}{\beta \cos \theta}
$$

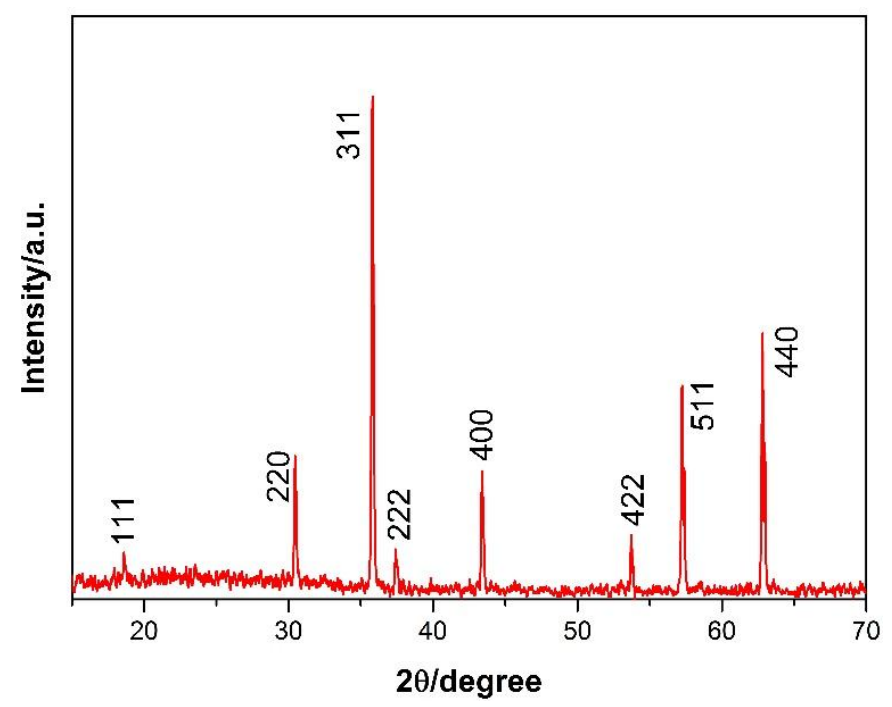

Fig. 1. XRD patterns of $\mathrm{MnFe}_{2} \mathrm{O}_{4}$ nanoparticles.

where $\beta$ is the full width at half-maximum (FWHM) of the strongest (311) XRD peak in radians in the $2 \theta$ scale, $K$ is the Debye-Scherrer constant $(\sim 0.94$ for spherical nanoparticles), $\lambda$ is the incident X-ray wavelength (1.5406 $\AA$ ), $\theta$ is the diffraction angle. Using Eq. 1, the average size of crystallite was estimated to be $59.6 \mathrm{~nm}$. 


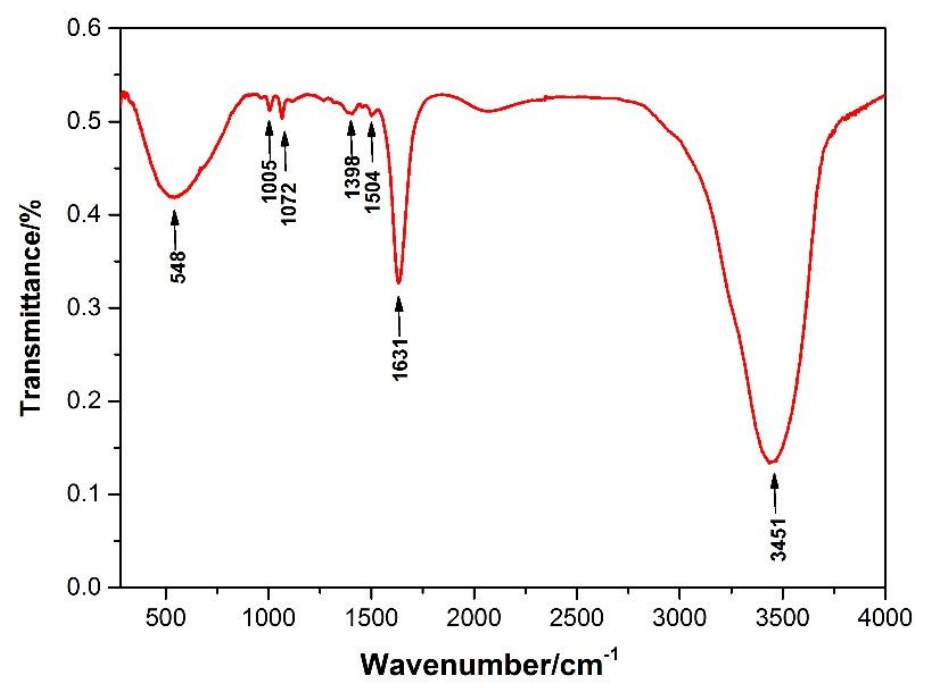

Fig. 2. FTIR spectra of $\mathrm{MnFe}_{2} \mathrm{O}_{4}$ nanoparticles.

Fig. 2 shows the FTIR spectrum of $\mathrm{MnFe}_{2} \mathrm{O}_{4}$ magnetic nanoparticles. The FTIR spectrum $\left(4000-400 \mathrm{~cm}^{-1}\right)$ of magnetic nanoparticles dispersed in $\mathrm{KBr}$ revealed that a broad band of MNPs at $548 \mathrm{~cm}^{-1}$ could be ascribed to $\mathrm{Mn}-\mathrm{O}$ stretching vibration which is a direct indication about the formation of $\mathrm{MnFe}_{2} \mathrm{O}_{4}$ magnetic nanoparticles with inverse spinel structure [16]. A broadband around $3451 \mathrm{~cm}^{-1}$ and $1631 \mathrm{~cm}^{-1}$ can be ascribed due to the $\mathrm{O}-\mathrm{H}$ stretching and bending vibration frequencies, respectively, of adsorbed water $[17,18]$ and DEA molecules. Since DEA is a secondary amine and a broadband band due to its $\mathrm{N}-\mathrm{H}$ stretching vibration mode expected to be appeared in the range of 3500-3300 $\mathrm{cm}^{-1}$ is vanishingly weak [19], the coincident of the expected weak $\mathrm{N}-\mathrm{H}$ stretching band with that of $\mathrm{O}-\mathrm{H}$ at $3451 \mathrm{~cm}^{-1}$ makes it difficult for distinct detection. However, several bands in the fingerprint region of range $1000-1510 \mathrm{~cm}^{-1}$ are detected. The peak mainly appeared at $1072 \mathrm{~cm}^{-1}$ is assigned due to the $\mathrm{C}-\mathrm{N}$ stretching vibration [19] indicating the adsorption of DEA on the surface of $\mathrm{MnFe}_{2} \mathrm{O}_{4}$ magnetic nanoparticles.

The amount of adsorbed water and DEA on the nanoparticles surface is further quantified by TGA. TGA results (Fig. 3 and Table 1) show two-step weight loss for $\mathrm{MnFe}_{2} \mathrm{O}_{4}$ magnetic nanoparticles. An initial weight loss in the temperature range of $30-120{ }^{\circ} \mathrm{C}$ may be attributed to the removal of physically adsorbed water in the sample [20]. The second significant weight loss within the range of $120-400{ }^{\circ} \mathrm{C}$ can be attributed to the decomposition of DEA bounded on the surface, as indicated by FTIR spectra. 


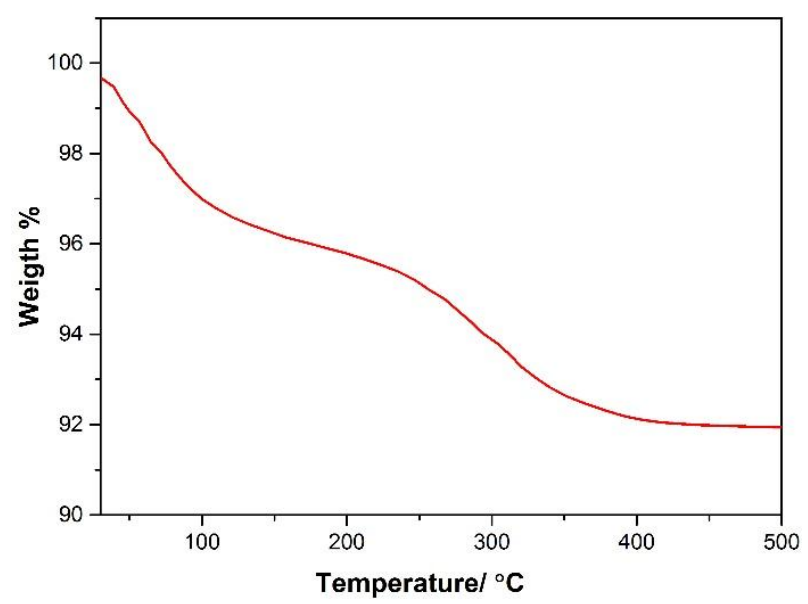

Fig. 3. TGA curves of $\mathrm{MnFe}_{2} \mathrm{O}_{4}$ nanoparticles.

Table 1. Chemical composition and partial weight loss.

\begin{tabular}{|c|c|c|c|c|c|}
\hline \multirow{2}{*}{ Nanomaterial } & \multicolumn{3}{|c|}{ EDX } & \multicolumn{2}{c|}{${ }^{\mathrm{a}}$ Partial weight loss \% } \\
\cline { 2 - 6 } & wt \% Mn & wt \% Fe & $\mathrm{Fe}:$ Mn molar ratio & $30-150{ }^{\circ} \mathrm{C}$ & $150-450{ }^{\circ} \mathrm{C}$ \\
\hline $\mathrm{MnFe}_{2} \mathrm{O}_{4}$ & 24.79 & 50.05 & 1.98 & $\sim 3$ & $\sim 5$ \\
\hline
\end{tabular}

${ }^{\text {a }}$ Partial weight loss was determined by TGA

The total metal content and thereby chemical composition of the synthesized $\mathrm{MnFe}_{2} \mathrm{O}_{4}$ samples was determined from Energy Dispersive X-ray (EDX) Spectroscopy (Fig. 4). The metal $(\mathrm{Mn}: \mathrm{Fe})$ in the prepared sample was calculated to be 1:1.98 (Table 1), which is a little lower than the theoretical stoichiometry and the chemical composition. This is likely due to partial surface oxidation or adsorption of alkanolamine on the nanomaterial surface [21] as confirmed by TGA.

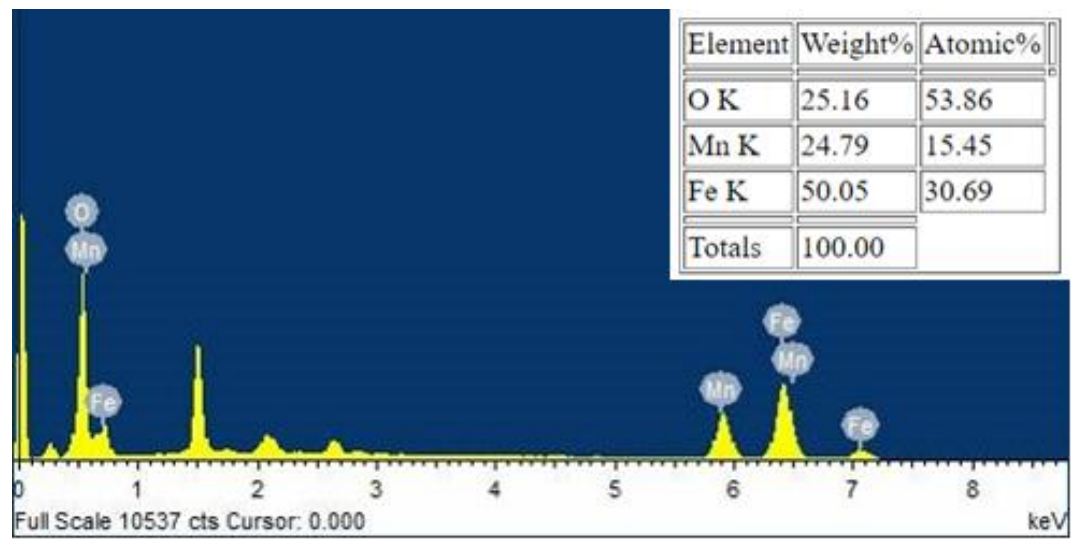

Fig. 4. EDX spectra of $\mathrm{MnFe}_{2} \mathrm{O}_{4}$ nanoparticles. 
The surface morphology of $\mathrm{MnFe}_{2} \mathrm{O}_{4}$ magnetic nanoparticles was studied with field emission scanning electron microscope (FESEM). The surface morphology and size distribution are shown in Fig. 5. From the histogram represented by Fig. 5(d) corresponding to FESEM image of Fig. 5(c), the average particle size of synthesized nanomaterial is estimated to $46.8 \mathrm{~nm}$. The size of grains was also determined from the XRD pattern using the Scherrer equation and found to be around $59.6 \mathrm{~nm}$ which is comparable to the value obtained from FESEM image. It is observed that the nanoparticles tend to somewhat agglomerate. This is likely due to the absence of an effective stabilizing agent. Being a small neutral molecule, DEA is not capable of providing steric or electrostatic stabilization to a greater extent.
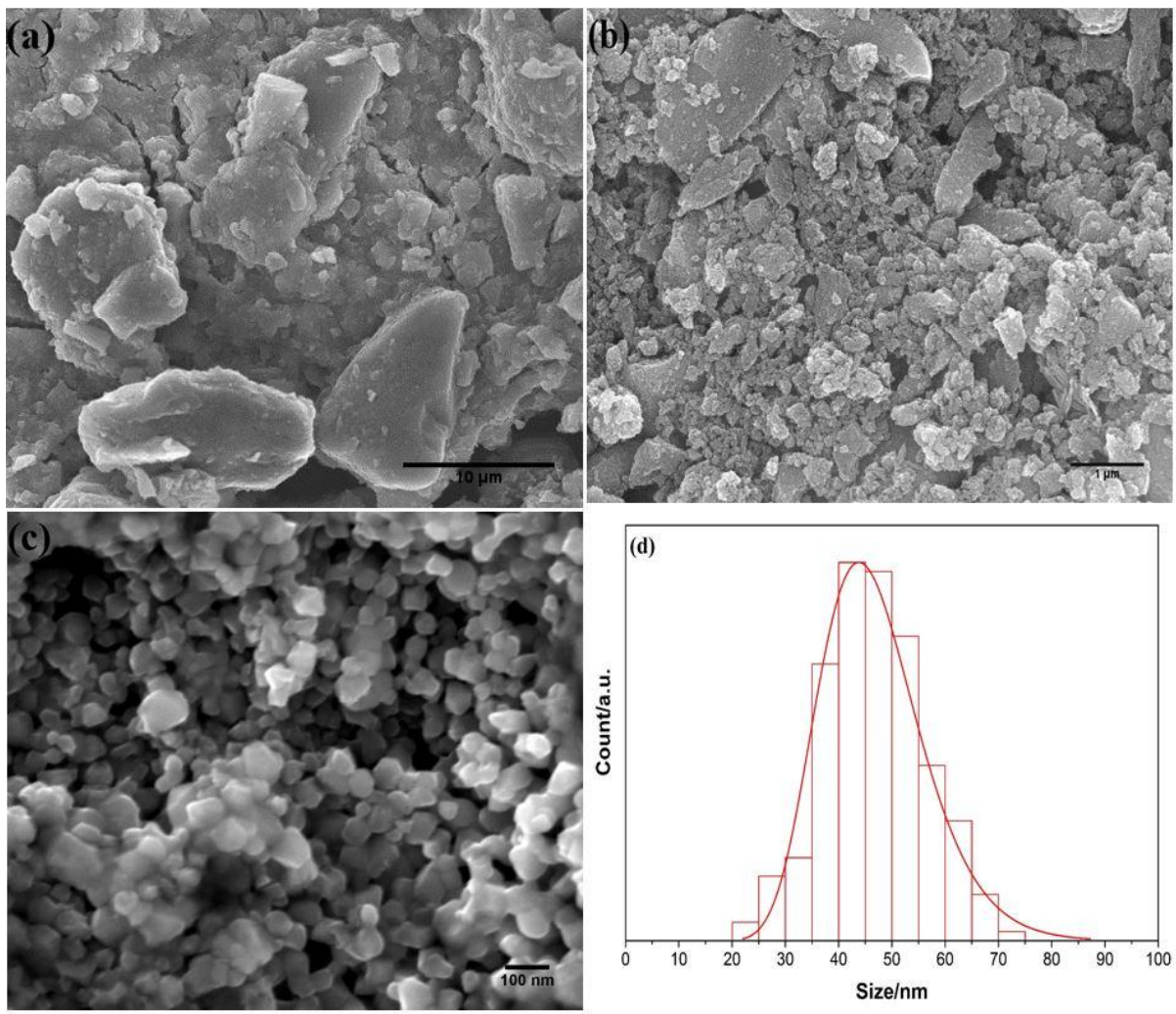

Fig. 5. FESEM images of $\mathrm{MnFe}_{2} \mathrm{O}_{4}$ nanoparticles at different magnifications; (a) low, (b) medium, and (c) high magnifications. The size distribution of $\mathrm{MnFe}_{2} \mathrm{O}_{4}$ nanoparticles calculated from FESEM image (c) is shown in (d).

\subsection{Magnetic property}

$\mathrm{M}-\mathrm{H}$ data of $\mathrm{MnFe}_{2} \mathrm{O}_{4}$ magnetic nanoparticles measured at $300 \mathrm{~K}$ are schematically illustrated in Fig. 6. Coercivity $\left(\mathrm{H}_{\mathrm{c}}\right)$, remanence $\left(\mathrm{M}_{\mathrm{r}}\right)$ and saturation magnetization $\left(\mathrm{M}_{\mathrm{s}}\right)$ obtained from measured $\mathrm{M}-\mathrm{H}$ data are presented in Table 2. It is discernible that the 
values $H_{c}$ and $M_{r}$ are quite small indicating the sample of superparamagnetic nature at $300 \mathrm{~K}$ temperature. The observed $\mathrm{M}_{\mathrm{s}}$ value of $77.31 \mathrm{emu} / \mathrm{g}$ is comparable to the reported [22] value of $78.3 \mathrm{emu} / \mathrm{g}$ for $47.3 \mathrm{~nm} \mathrm{MnFe}_{2} \mathrm{O}_{4}$ nanoparticles synthesized through complicated hydrothermal method followed by calcination process. It is also noted that $\mathbf{M}_{\mathrm{s}}$ value is slightly less than the bulk value of $80 \mathrm{emu} / \mathrm{g}$ at $300 \mathrm{~K}$ [23]. This is probably due to the imperfect cations distribution between different crystallographic tetrahedral and octahedral sublattices in the inverse spinel structure [24]. The critical diameter, assuming spherical particles, below which the particles possess superparamagnetic behavior for manganese ferrite is $42.9 \mathrm{~nm}[25,26]$. Since the diameter ( $46.8 \mathrm{~nm}$ measured by FESEM) of the synthesized nanoparticles is closed to the critical diameter with little coercivity (10.53 emu/g) and remanence $(9.32 \mathrm{emu} / \mathrm{g})$, the synthesized nanoparticles show nearly superparamagnetic behavior.

Table 2. Morphology and magnetic property.

\begin{tabular}{|l|l|l|l|l|l|}
\hline Nanomaterial & $\left\langle\mathrm{d}_{\mathrm{XRD}}>\mathrm{nm}^{\mathrm{a}}\right.$ & $\left\langle\mathrm{d}_{\mathrm{SEM}}>\mathrm{nm}^{\mathrm{b}}\right.$ & $\mathrm{M}_{\mathrm{S}}(\mathrm{emu} / \mathrm{g})^{\mathrm{c}}$ & $\mathrm{H}_{\mathrm{C}}(\mathrm{Oe})^{\mathrm{d}}$ & $\mathrm{M}_{\mathrm{r}}(\mathrm{emu} / \mathrm{g})^{\mathrm{e}}$ \\
\hline $\mathrm{MnFe}_{2} \mathrm{O}_{4 \_} \mathrm{DEA}$ & 59.6 & 46.8 & 77.31 & 10.53 & 9.32 \\
\hline
\end{tabular}

${ }^{a}$ Average crystallite size as estimated by XRD. ${ }^{b}$ Average particle size as estimated by SEM assuming a lognormal particle size distribution. ${ }^{\mathrm{c}}$ Saturation magnetization (the maximum possible magnetization). ${ }^{\mathrm{d}}$ Coercivity (the intensity of the applied magnetic field required to reduce the magnetization of nanoparticles to

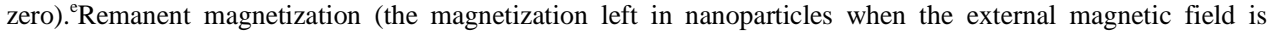
removed).

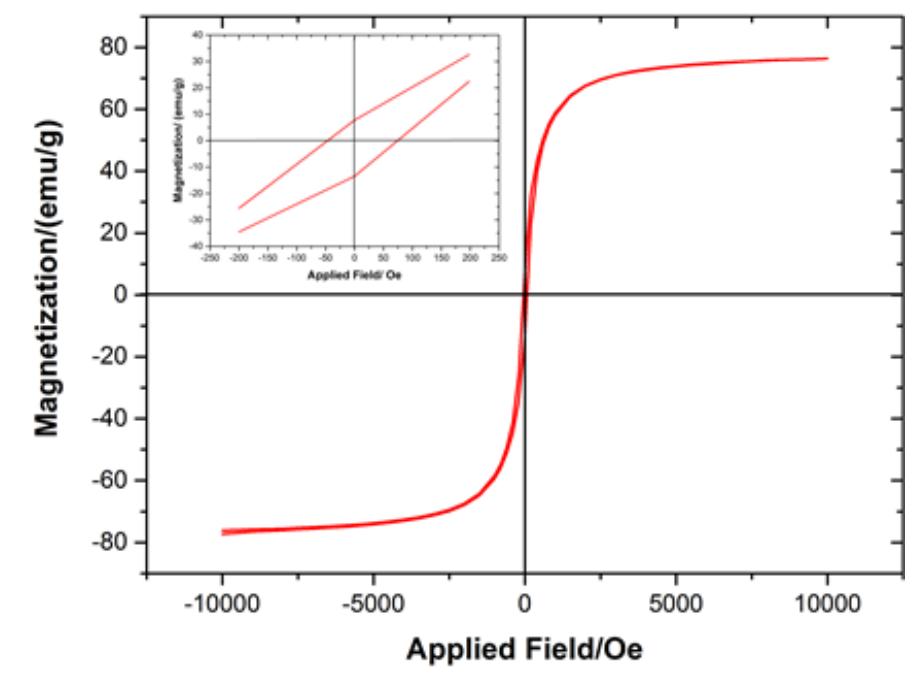

Fig. 6. Magnetization curve of $\mathrm{MnFe}_{2} \mathrm{O}_{4}$ nanoparticles measured at $300 \mathrm{~K}$.

\section{Conclusion}

In summary, $\mathrm{MnFe}_{2} \mathrm{O}_{4}$ nanoparticles were synthesized by one-step aqueous coprecipitation route using DEA organic base. The use of DEA base furnished a simple, versatile, and cost-effective co-precipitation route for the high-yield synthesis of $\mathrm{MnFe}_{2} \mathrm{O}_{4}$ 
MNPs featuring improved magnetic properties. DEA functioned as both of the precipitating and capping agent. The synthesized nanoparticles exhibited high saturation magnetization with little coercivity and remanence. It is believed that the use of organic base in co-precipitation synthetic route is highly desired for a step forward design and high yields of nanomaterials with the potential interest of various applications.

\section{Acknowledgment}

Financial support from the Ministry of Science and Technology, Government of Bangladesh (Grant No.409 -5ID) is acknowledged. The authors greatly appreciate access to the XRD and VSM equipment provided Bangladesh Atomic Energy Center, Dhaka.

\section{References}

1. U. Jeong, X. Teng, Y. Wang, H. Yang, and Y. Xia, Adv. Mater. 19, 33 (2007). https://doi.org/10.1002/adma.200700149

2. A. Lu, E. Salabas and F. Schüth, Angew. Chemie Int. Ed. 46, 1222 (2007). https://doi.org/10.1002/anie.200602866

3. S. Laurent, D. Forge, M. Port, A. Roch, C. Robic, L. Vander Elst, and R.N. Muller, Chem. Rev. 108, 2064 (2008). https://doi.org/10.1021/cr068445e

4. N. A. Frey, S. Peng, K. Cheng and S. Sun, Chem. Soc. Rev. 38, 2532 (2009). https://doi.org/10.1039/b815548h

5. M.-K. Kim, J. Sim, J.-H. Lee, M. Kim, and S.-K. Kim, Phys. Rev. Appl. 9, 54037 (2018). https://doi.org/10.1103/PhysRevApplied.9.064005

6. W. Wu, Q. He, and C. Jiang, Nanoscale Res. Lett. 3, 397 (2008). https://doi.org/10.1007/s11671-008-9124-6

7. J. S. Salazar, L. Perez, O. de Abril, L. T. Phuoc, D. Ihiawakrim, M. Vazquez, J.-M. Greneche, S. Begin-Colin, and G. Pourroy, Chem. Mater. 23, 1379 (2011). https://doi.org/10.1021/cm103188a

8. H. J. Lee, J. We, J.O. Kim, D. Kim, W. Cha, E. Lee, J. Sohn, and M. Oh, Angew. Chemie Int. Ed. 54, 10564 (2015). https://doi.org/10.1002/anie.201504466

9. Y. Jun, J. Seo, and J. Cheon, Acc. Chem. Res. 41, 179 (2008). https://doi.org/10.1021/ar700121f

10. X. Batlle, N. Pérez, P. Guardia, O. Iglesias, A. Labarta, F. Bartolomé, L. M. García, J. Bartolomé, A. G. Roca, and M. P. Morales, J. Appl. Phys. 109, 07B524 (2011). https://doi.org/10.1063/1.3559504

11. Y. Yuan, D. Rende, C. L. Altan, S. Bucak, R. Ozisik, and D.-A. Borca-Tasciuc, Langmuir 28, 13051 (2012). https://doi.org/10.1021/la301416e

12. Y. Köseoğlu, J. Magn. Magn. Mater. 300, 327 (2006). https://doi.org/10.1016/j.jmmm.2005.10.112

13. C. Pereira, A.M. Pereira, C. Fernandes, M. Rocha, R. Mendes, M.P. Fernández-García, A. Guedes, P. B. Tavares, J.-M. Grenèche, and J. P. Araújo, Chem. Mater. 24, 1496 (2012). https://pubs.acs.org/doi/abs/10.1021/cm300301c

14. F. M. Al-Sogair, B. P. Operschall, A. Sigel, H. Sigel, J. Schnabl, and R. K. O. Sigel, Chem. Rev. 111, 4964 (2011). https://doi.org/10.1021/cr100415s

15. C. Pereira, A. M. Pereira, P. Quaresma, P. B. Tavares, E. Pereira, J. P. Araújo, and C. Freire, Dalt. Trans. 39, 2842 (2010). https://doi.org/10.1039/b920853d

16. R. D. Waldron, Phys. Rev. 99, 1727 (1955). https://doi.org/10.1103/PhysRev.99.1727

17. K. Petcharoen and A. Sirivat, Mater. Sci. Eng. B 177, 421 (2012). https://doi.org/10.1016/j.mseb.2012.01.003 


\section{Manganese Ferrite Nanoparticles}

18. M. V Limaye, S. B. Singh, S. K. Date, D. Kothari, V. R. Reddy, A. Gupta, V. Sathe, R. J. Choudhary, and S. K. Kulkarni, J. Phys. Chem. B 113, 9070 (2009). https://doi.org/10.1021/jp810975v

19. D. L. Pavia, G. M. Lampman, G. S. Kriz, and J. R. Vyvyan, Introduction to Spectroscopy (Cengage Learning, Stamford, 2014).

20. A. Mohammadi and M. Barikani, Mater. Charact. 90, 88 (2014). https://doi.org/10.1016/j.matchar.2014.01.021

21. Y. Sahoo, A. Goodarzi, M. T. Swihart, T. Y. Ohulchanskyy, N. Kaur, E. P. Furlani, and P. N. Prasad, J. Phys. Chem. B 109, 3879 (2005). https://doi.org/10.1021/jp050202n

22. M. Y. Rafique, P. Li-Qing, M. Z. Iqbal, Q. Hong-Mei, M. H. Farooq, G. Zhen-Gang, and M. Tanveer, Chinese Phys. B 22, 107101 (2013). https://doi.org/10.1088/1674-1056/22/10/107101

23. R. M. Bozorth, E. F. Tilden, and A. J. Williams, Phys. Rev. 99, 1788 (1955). https://doi.org/10.1103/PhysRev.99.1898

24. E. Solano, C. Frontera, T. Puig, X. Obradors, S. Ricart, and J. Ros, J. Appl. Crystallogr. 47, 414 (2014). https://doi.org/10.1107/S1600576714017452

25. D. L. Leslie-Pelecky and R. D. Rieke, Chem. Mater. 8, 1770 (1996). https://doi.org/10.1021/cm960077f

26. C. Liu and Z. J. Zhang, Chem. Mater. 13, 2092 (2001). https://doi.org/10.1021/cm000017g 